\title{
An Increased Prevalence of Epstein-Barr Virus Infection in Young Patients Suggests a Possible Etiology for Systemic Lupus Erythematosus
}

\author{
Judith A. James, ${ }^{\star \ddagger}$ Kenneth M. Kaufman, ${ }^{\star \ddagger}$ A. Darise Farris, ${ }^{\ddagger}$ Elizabeth Taylor-Albert, ${ }^{\star \ddagger}$ Thomas J.A. Lehman, \\ and John B. Harley $\neq \S$ \\ *Department of Medicine, University of Oklahoma Health Sciences Center, ${ }^{\ddagger}$ Oklahoma Medical Research Foundation, and ${ }^{\S}$ U.S. \\ Department of Veterans Affairs Medical Center, Oklahoma City, Oklahoma 73104; and "Hospital for Special Surgery, New York 10021
}

\begin{abstract}
An unknown environmental agent has been suspected to induce systemic lupus erythematosus (lupus) in man. Prompted by our recent immunochemical findings, we sought evidence for an association between Epstein-Barr virus infection and lupus. Because the vast majority of adults have been infected with Epstein-Barr virus, we chose to study children and young adults. Virtually all (116 of 117, or 99\%) of these young patients had seroconverted against EpsteinBarr virus, as compared with only 70\% (107 of 153) of their controls (odds ratio 49.9, 95\% confidence interval 9.3-1025, $P<0.00000000001)$. The difference in the rate of EpsteinBarr virus seroconversion could not be explained by serum IgG level or by cross-reacting anti-Sm/nRNP autoantibodies. No similar difference was found in the seroconversion rates against four other herpes viruses. An assay for Epstein-Barr viral DNA in peripheral blood lymphocytes established Epstein-Barr virus infection in the peripheral blood of all 32 of the lupus patients tested, while only 23 of the 32 matched controls were infected (odds ratio $>10,95 \%$ confidence interval $2.53-\infty, P<0.002$ ). When considered with other evidence supporting a relationship between Epstein-Barr virus and lupus, these data are consistent with, but do not in themselves establish, Epstein-Barr virus infection as an etiologic factor in lupus. (J. Clin. Invest. 1997. 100:3019-3026.) Key words: autoimmunity • autoantibodies • viral infection • autoimmune disease $\cdot$ SLE
\end{abstract}

\section{Introduction}

Systemic lupus erythematosus (lupus) is an idiopathic disease characterized by variable inflammatory destruction of skin, joints, blood elements, kidneys, serosa, nervous system, and other tissues (1). In addition, the presence of autoantibodies, as manifest most consistently by a positive antinuclear antibody test, are nearly universal in lupus. A variety of autoantibodies are found in the serum of lupus patients, and constitute evidence that lupus is an autoimmune disease.

We have sought an etiology for lupus based upon the assumption that an understanding of the structural relationships

Address correspondence to J.A. James or J.B. Harley, University of Oklahoma, Oklahoma Medical Research Foundation, 825 N.E. Thirteenth, Oklahoma City, OK 73104. Phone: 405-271-7774; FAX: 405271-4110; E-mail: john-harley@omrf.ouhsc.edu

Received for publication 1 July 1997 and accepted in revised form 7 October 1997.

The Journal of Clinical Investigation

Volume 100, Number 12, December 1997, 3019-3026

http://www.jci.org between antigen and antibody would lead towards the immune responses that we have presumed are responsible for initiating lupus autoimmunity. Autoantibodies against the spliceosome, also referred to as anti-Sm and anti-nRNP, are common in lupus, being found in $\sim 25-40 \%$ of patients. Autoantibodies binding the peptide PPPGMRPP, derived from the amino acid sequence of $\mathrm{Sm} \mathrm{B} / \mathrm{B}^{\prime}$, appear to be among the earliest to develop in the humoral autoimmune response against the $B / B^{\prime}$ protein of the $\mathrm{Sm}$ antigen (2). Immunization with this peptide induces lupus-like autoimmunity in animals (2), as does immunization with the closely related sequence PPPGRRP, found in the Epstein-Barr nuclear antigen-1 (EBNA-1; 3). ${ }^{1}$

Perhaps these structural and immunogenic relationships between EBNA-1 and the fine specificity of the autoantigenic history of the spliceosome in lupus reflect an etiology of lupus. It is possible that an immune response directed against PPPGRRP of EBNA-1 develops antibodies that cross-react with PPPGMRPP in the spliceosome, inducing lupus autoimmunity in some patients after a molecular mimicry mechanism.

If the hypothesis that Epstein-Barr virus is a possible etiology for lupus were true, there must be an association between Epstein-Barr virus infection and lupus. Such an association would not prove this hypothesis; however, the absence of an association would disprove the hypothesis. The lifelong latency of this virus after infection and the constant immune stimulation deriving therefrom make this virus an intriguing candidate for an environmental agent capable of inducing lupus. The high prevalence of Epstein-Barr infection in adults ( $\sim 95 \%$ have been infected and are presumed to carry the virus [4]) would mean that other factors must also be important if Epstein-Barr virus was shown to be a required participant.

To have sufficient statistical power to determine whether the predicted association between Epstein-Barr virus and lupus exists, the experiments were performed in children and young adults (all $<20 \mathrm{yr}$ of age) where the frequency of virus infection in normal individuals is substantially lower than that found in the adult population. In the United States, about half of the population is infected with Epstein-Barr virus between the ages of 10 and $20 \mathrm{yr}$ (4).

We are not the first to explore a relationship between Epstein-Barr virus and lupus. The first serious attempt was published over a quarter century ago (5). Despite the dramatically less sensitive and specific methods available at that time, a higher level of antivirus antibody was found in these patients than in the controls. The ratio of patient to control titer was 6.14:1 ( $P<0.001$ from data in reference 5). Some of these same authors found inconsistent results in subsequent studies published in $1973(6,7)$. Since then, the prevailing opinion has

1. Abbreviations used in this paper: EBNA, Epstein-Barr virus nuclear antigen; EBV-VCA, Epstein-Barr virus nuclear antigen viral capsid antigen antibodies; ISR, international standardized ratio. 
been that lupus is not directly related to Epstein-Barr virus infection. We reexamine this question using the much more reliable technologies now available, and an experimental design chosen to improve statistical power. The results obtained demonstrate an association between lupus and Epstein-Barr virus infection sufficiently powerful to suggest that Epstein-Barr virus infection is in some way related to the vast majority of lupus cases.

\section{Methods}

Patients and controls. All subjects were between 4 and $19 \mathrm{yr}$ of age. Lupus patients satisfy the 1982 criteria for lupus (1). The Oklahoma City lupus patients and controls were similar by age (15.79 \pm 2.15 and $15.40 \pm 2.51 \mathrm{yr}$ ), race (European-American, 53 and 59\%; AfricanAmerican, 27 and 23\%; Hispanic, 10 and 9.5\%; and other, 10 and $8.5 \%$ ), and sex (85 and $82 \%$ female). Controls in the San Diego group were selected from siblings. For the matched case control study, controls were matched for age $( \pm 2 \mathrm{yr})$, sex, race, and social situation (cases selected controls when possible). In addition, we have two collections of children with other rheumatic diseases, juvenile rheumatoid arthritis, and myositis. These serum samples were generously provided by Dr. Morris Reichlin and the Childhood Myositis Heterogeneity Study Group.

Serologic assays. Antinuclear antibody assays, antispliceosomal antibodies, antispliceosomal antibody absorptions, and IgG levels were performed as previously described (8-10).

Antiviral assays were performed as instructed by Wampole Laboratories (Cranberry, NJ), or for retesting by Gull Laboratories (Salt Lake City, UT). The assay methods and analysis are presented as units of the international standardized ratio (ISR), which is designed to be as accurate as possible for precise detection of seroconversion. Since the ISR is linear with the optical density, the higher levels of antibody will be relatively underestimated. Nevertheless, the ISR is a semiquantitative measure of the relative level of antibody.

Epstein-Barr virus DNA detection. The Epstein-Barr virus DNA assay was modified from previous methods $(11,12)$ using peripheral blood mononuclear cell DNA and the PCR with the forward $5^{\prime}$-CCAGAGGTAAGTGGACTT-3' and reverse primers 5'-GACCGGTGCCTTCTTAGG-3' . A positive result produced a 122-nucleotide (nt) DNA fragment that was sequenced and found to be identical to the previously published sequence (position 14,614-14,735, Genbank accession no. V01555). PCR products were Southern-blotted with a $\left[{ }^{32} \mathrm{P}\right] \mathrm{dCTP}-\mathrm{labeled}$ probe corresponding to positions $14,639-14,676$. This fragment was cloned into pCRII and sequenced using the dideoxy method (13). The sequence obtained matched the expected DNA sequence exactly. Flanking primers (position 14,557-14,574 and 14,759-14,776) were used to confirm results.

For every specimen from which DNA was isolated, six PCRs were evaluated, each containing $2 \mu \mathrm{g}$ of mononuclear cell DNA. Reactions contained $50 \mathrm{mM} \mathrm{KCl}, 10 \mathrm{mM}$ Tris- $\mathrm{HCl}$ at $\mathrm{pH} 8.0,1.5 \mathrm{mM}$ $\mathrm{MgCl}_{2}, 0.1 \%$ Triton X-100, and $0.2 \mathrm{mM}$ each of dNTP, $0.5 \mu \mathrm{M}$ primer, and 2.5 U Taq DNA polymerase. Hot-start protocol was performed using Ampliwax PCR Gems (Perkin-Elmer, Branchburg, $\mathrm{NJ}$ ). The cycles used were as follows: $2 \mathrm{~min}$ at $95^{\circ} \mathrm{C}, 1 \mathrm{~min}$ at $59^{\circ} \mathrm{C}, 1$ min at $72^{\circ} \mathrm{C}$ (twice); $2 \mathrm{~min}$ at $94^{\circ} \mathrm{C}, 1 \mathrm{~min}$ at $58^{\circ} \mathrm{C}, 1 \mathrm{~min}$ at $72^{\circ} \mathrm{C}$ (twice); $1 \mathrm{~min}$ at $94^{\circ} \mathrm{C}, 1 \mathrm{~min}$ at $57^{\circ} \mathrm{C}, 45 \mathrm{~s}$ at $72^{\circ} \mathrm{C}$ (31 times); and 5 $\min$ at $72^{\circ} \mathrm{C}$.

All samples that were negative for Epstein-Barr virus DNA by the first set of primers were tested for expansion of a 132-nt fragment of $60 \mathrm{kD}$ Ro: (forward) 5'-CATGAAATGTGGCATG TGGG-3' and (reverse) 5'-AGATCTTTGTGAGACCAGCC-3'. The expanded fragment was present in every sample tested.

All samples negative for Epstein-Barr virus DNA were also tested by PCR for a unique set of polymorphisms from the M13 Map Pair primers from D1S1589, D2S1328, D6S1027, D1S1678, D18S535, and DXS6810 (Research Genetics, Huntsville, Alabama). PCR prod- ucts were separated, and DNA sequences were obtained on a model 4000L DNA sequencer (LI-COR, Lincoln, NE).

Statistics. The Breslow-Day test was used to test for homogeneity of odds ratios by site of subject colection. The mid $P$ exact confidence intervals for the odds ratios were calculated using EXACT (Version 2.0b). The probability of the observed frequencies of seroconversion was calculated by the Fisher exact test. SAS programs (Sas Institute, Cary, NC) were used for stepwise logistic regression. Where normal distributions could not be assumed, nonparametric testing, including median, $25-75 \%$ interquartile ranking (IQR), and Wilcoxan Rank test of the means were also calculated by the SAS programs. The binomial test was used to calculate probabilities for the discordant matched cases and controls. To estimate odds ratios when relevant zero cells were encountered, one was added to all cells.

\section{Results}

Anti-Epstein-Barr virus viral capsid antigen antibodies (anti$E B V-V C A)$. To test for an association between lupus and serologic conversion against Epstein-Barr virus, serum (or plasma) from young lupus patients was collected in Oklahoma City. Local controls were assembled to reflect the age, racial composition, and sex of the cases. The preliminary analysis of the cases and controls collected in Oklahoma City suggested that an association between lupus and anti-EBV-VCA antibodies was present. This finding was confirmed as the collection was enlarged (Table I).

Confirmation of this association was also sought by repeating the experiment in a second group of cases and controls. A previously assembled collection of sera from families with a pediatric lupus proband from the San Diego area was evaluated for Epstein-Barr virus seroconversion by the anti-EBVVCA assay. Sera simultaneously collected from the siblings of the San Diego probands were used as controls.

The young lupus patients from both the Oklahoma City and San Diego cohorts have a much higher rate of EBV-VCA seroconversion than do their respective controls (Table I). Indeed, the Breslow-Day test suggests that the EBV-VCA seroconversion rates of patients and controls collected in Oklahoma and California are statistically homogeneous $(P>0.05)$, and therefore may be combined.

Of the entire collection of 117 young lupus patients, 116 have seroconverted against EBV-VCA (Table I). Meanwhile,

Table I. Seroconversion Against Epstein-Barr Virus Viral Capsid Antigen (EBV-VCA) in Sera from Young Lupus Patients and Controls

\begin{tabular}{lccc}
\hline & Oklahoma City & San Diego & Combined* \\
\hline & No. pos (total) & No. pos (total) & No. pos (total) \\
& $59(59)$ & $57(58)$ & $116(117)$ \\
Lupus patients & $64(95)$ & $43(58)$ & $107(153)$ \\
Normal controls & & & 49.9 \\
Odds ratio & & & $9.3,1025$ \\
95\%-CI of O.R. & & & 0.00000000000421 \\
Probability & & & \\
& & &
\end{tabular}

Sera from lupus patients (cases) or their controls were tested for IgG anti-EBV-VCA antibodies and standardized for seroconversion. No. pos, number seroconverted. *Since the Breslow-Day test for homogeneity of the odds ratios shows that they are not statistically different in the Oklahoma City and San Diego collections of patients and controls, the two groups have been combined for analysis. "Fisher’s exact test. 
only $70 \%$, or 107 of 153 of the controls, have seroconverted against EBV-VCA. In these patients and controls, EpsteinBarr virus seroconversion is very closely associated with lupus, with an odds ratio of 49.9 . The $95 \%$ confidence interval for the odds ratio is quite broad (9.3-1035), suggesting that while the association between EBV-VCA seroconversion is convincing, knowing the true magnitude of the association will require a much larger collection of patients and controls. The likelihood that the distribution observed could have occurred by chance is, however, vanishingly small $(P<0.00000000000421)$.

Anti-EBV-VCA IgM was tested in 23 lupus patients' sera and 22 controls to assess if children with SLE have an abberrant IgM-EBV response, or if seronegative controls have been recently exposed to EBV. No anti-EBV-VCA IgM was found in any of these sera. These results suggest that of those who have anti-EBV-VCA IgG evidence of seroconversion, infection with Epstein-Barr virus was in the immunologically distant past.

We have evaluated two groups of control sera from children with other autoimmune rheumatic diseases. 38 children with juvenile rheumatoid arthritis have been tested for IgG binding to EBV-VCA. 29 of the 38 children (72.1\%) have evidence of previous exposure to EBV. We have tested 36 childhood myositis patients' sera for anti-EBV-VCA antibodies. 26 of 36 children $(72.2 \%)$ with clinical and serological evidence of myositis had antibodies to EBV-VCA. Neither of these rheumatic disease subsets showed a significantly greater incidence of EBV exposure than did sera from the two groups of normal control children presented above. An association between either childhood myositis or juvenile rheumatoid arthritis and seroconversion against Epstein-Barr virus would appear to be unlikely, especially at the level found in the two cohorts of young lupus patients presented above.

The powerful association of Epstein-Barr virus seroconversion with lupus has the potential to reorient much thinking concerning the origin of lupus unless the association is explained by some relatively trivial issue. A series of experiments were therefore performed to assess the potential that this close association could be the result of an experimental artifact. We measured the extent of autoantibody cross-reaction with EBV-VCA for the specific example of the spliceosome (Sm/ nRNP) by absorption. IgG levels were compared between lupus patient and normal control sera in an effort to assess a possible contribution of hypergamma-globulinemia. In addition, seroconversion against four other herpes viruses was measured. Finally and most importantly, a technically independent assay was developed and applied that directly detected the presence of Epstein-Barr virus DNA in lupus cases and their matched controls. All of these experiments supported a close association between Epstein-Barr virus infection and lupus, as presented below.

Antispliceosomal antibody absorption. Cross-reactivity between EBV-VCA and the spliceosome was evaluated by testing for anti-EBV-VCA antibodies before and after absorbing the antispliceosomal autoantibodies from five anti-Sm precipitin-positive lupus sera. These sera were specifically selected because their primary autoantibody responses were directed against the spliceosomal proteins. Absorption reduced the antispliceosome activity as measured by binding to the purified bovine nuclear ribonucleoprotein (the U1 particle) by at least $90 \%$, and reduced the fluorescent antinuclear antibody binding by an average of $97 \%$ (thereby supporting the contention that the spliceosome is the major autoantigen in these particular anti-Sm precipitin-positive patients). Absorption reduced the IgG anti-EBV in these sera by an average of $8 \%$, but did not alter the EBV seroconversion status of any of these antiSm precipitin-positive lupus sera (supporting the absence of a quantitatively relevant level of $\mathrm{IgG}$ cross-reactivity between EBV-VCA and the spliceosome).

IgG levels. Nonspecific binding is sometimes found in lupus sera. One explanation for positive results as a result of nonspecific binding is the hypergammaglobulinemia found in some lupus sera. IgG levels were assessed in 28 of the lupus sera and in 28 of the control sera. These control sera were primarily siblings of the lupus probands. The IgG levels were not different between these groups, nor did the IgG level correlate with the level of anti-EBV-VCA (data not presented). The mean level of IgG in lupus patient sera may have been lowered by the inclusion of many patients who had been treated with high-dose prednisone ( $>40 \mathrm{mg} / \mathrm{d})$ and cytotoxic agents. The level may have been increased in the controls, because most of those selected (19 of 28) were relatives of lupus patients.

Alternative $E B V$-VCA preparation. To be certain that the binding to EBV-VCA by lupus sera was not an artifact of the particular EBV-VCA preparation, a second source of this antigen was used. We re-tested 32 lupus sera and 47 control sera. In the lupus patients, the two assays for Epstein-Barr virus seroconversion produced identical results. There were only minor differences in the control sera where three that had earlier been equivocal, and hence seronegative, were anti-EpsteinBarr virus-seropositive in this second assay. This experiment confirmed the unexpectedly high frequency of Epstein-Barr virus seropositivity in lupus patients (odds ratio $=19.24 ; 95 \%$ confidence interval $[\mathrm{CI}]=3.06-121.1$ ).

Seroconversion against other herpes viruses. The Oklahoma City and San Diego cases and controls were evaluated for IgG against four other herpes viruses: cytomegalovirus, herpes simplex virus types 1 and 2, and varicella zoster virus. The differences in the seroconversion rates against these viruses between cases and controls (Table II) were much smaller than those ob-

Table II. Seroconversion Frequencies in Pediatric Lupus and Controls for IgG Binding to Cytomegalovirus Antigen (CMV), Herpes Simplex Type 1 Antigen (HSV-1), Herpes Virus Type 2 Antigen (HSV-2), and Varicella Zoster Virus (VZV) Antigens

\begin{tabular}{|c|c|c|c|c|}
\hline & CMV & HSV-1 & HSV-2 & VZV \\
\hline \multicolumn{5}{|l|}{ Oklahoma City } \\
\hline Lupus patients & $24(59)$ & $39(59)$ & $27(59)$ & $56(59)$ \\
\hline Normal controls & $28(95)$ & $43(96)$ & $28(96)$ & $87(96)$ \\
\hline \multicolumn{5}{|l|}{ San Diego } \\
\hline Lupus patients & $18(58)$ & $33(58)$ & $32(58)$ & $46(58)$ \\
\hline Normal controls & $12(57)$ & $31(57)$ & $23(57)$ & $45(57)$ \\
\hline Odds ratio & 1.57 & 1.71 & 2.03 & 1.08 \\
\hline CI-95\% of odds ratio & $0.93,2.65$ & $1.05,2.79$ & $1.24,3.34$ & $0.53,2.24$ \\
\hline Probability & 0.11 & 0.036 & 0.0059 & 0.86 \\
\hline
\end{tabular}

Sera from lupus patients (cases) or their controls were tested for IgG antiviral antibodies and standardized for seroconversion. The odds ratios were calculated after combining both groups since the Breslow-Day test shows that the individual odds ratios are homogeneous. 
served against Epstein-Barr virus (Table I). The odds ratios for a seroconversion rate difference for cytomegalovirus and varicella zoster did not differ significantly from unity. There were potentially significant differences between patients and controls for herpes simplex virus types 1 and 2 .

For herpes simplex type 1, the Breslow-Day test shows that the Oklahoma City and San Diego results are not sufficiently different to require separate analyses. This outcome may be the result of a relatively small sample size of the groups being tested, since the Oklahoma City collection has an odds ratio of 2.4 (nearly twice that of 1.1 found in the San Diego collection). In any case, this seroconversion difference is unlikely to be important since it is of relatively small magnitude and is not consistently found in both collections of patients and controls.

On the other hand, there is a higher rate of seroconversion against herpes simplex virus type 2 in the cases than is found in the controls from both sites. Also, the odds ratios are similar, and the cumulative significance is consistent with this being a difference between young lupus patients and controls in both communities. Relative to the odds ratio for an association of lupus with Epstein-Barr virus (odds ratio $=49.9$ ), however, the odds ratio for an association with herpes virus type 2 (odds ratio $=2.03$ ) is small (Tables I and II).

To determine whether there might be an independent association of lupus with Epstein-Barr virus and herpes simplex virus type 2, stepwise logistic regression was applied to these data using lupus as the dependent variable and the seroconversion status of all five viruses as independent variables. EpsteinBarr virus is incorporated into the model first (odds ratio $=49$, score $\chi^{2}=39$, degrees of freedom $\left.[\mathrm{df}]=1, P=0.0000000005\right)$.
The residual $\chi^{2}$ is so small $\left(\chi^{2}=6.8, \mathrm{df}=4, P=0.15\right)$ that no further model building is indicated. In these cases and controls, the association between lupus and Epstein-Barr virus is $10^{8}$ fold more significant than it is between lupus and any of the other viruses evaluated. Consequently, beyond the effect of Epstein-Barr virus, none of the other viruses make a meaningful contribution to the overall model, and the high level of Epstein-Barr virus seroconversion cannot be explained by the presence of nonspecific antiviral antibodies.

Levels of antiherpes virus antibodies. The specific association between Epstein-Barr virus seroconversion presented above (Table I) is dependent upon the quantitative levels of antibody only to the extent that the threshold for seroconversion has or has not been exceeded.

The ISR difference of anti-EBV-VCA antibodies between the lupus patients and their controls is impressive: 4.30 vs. 1.92 ISR $\left(Z=10.69, P=1.13 \times 10^{-26}\right)$. The differences in the levels of the other antiherpes antibodies is much smaller (Fig. 1). Of these, only antibodies against the herpes simplex virus types 1 and 2 appear to achieve significance $(Z=3.59, P=$ 0.00034 ; and $Z=5.41, P=6.1 \times 10^{-8}$, respectively), again in concert with the results obtained above by assessing seroconversion rates.

Epstein-Barr virus DNA assay. In aggregate, the data presented above support a specific association between EpsteinBarr virus seroconversion and lupus. To test rigorously the prediction that Epstein-Barr virus infection is associated with lupus, a matched case control study has also been performed using the presence of DNA from Epstein-Barr virus in peripheral blood mononuclear cells as evidence for Epstein-Barr vi-
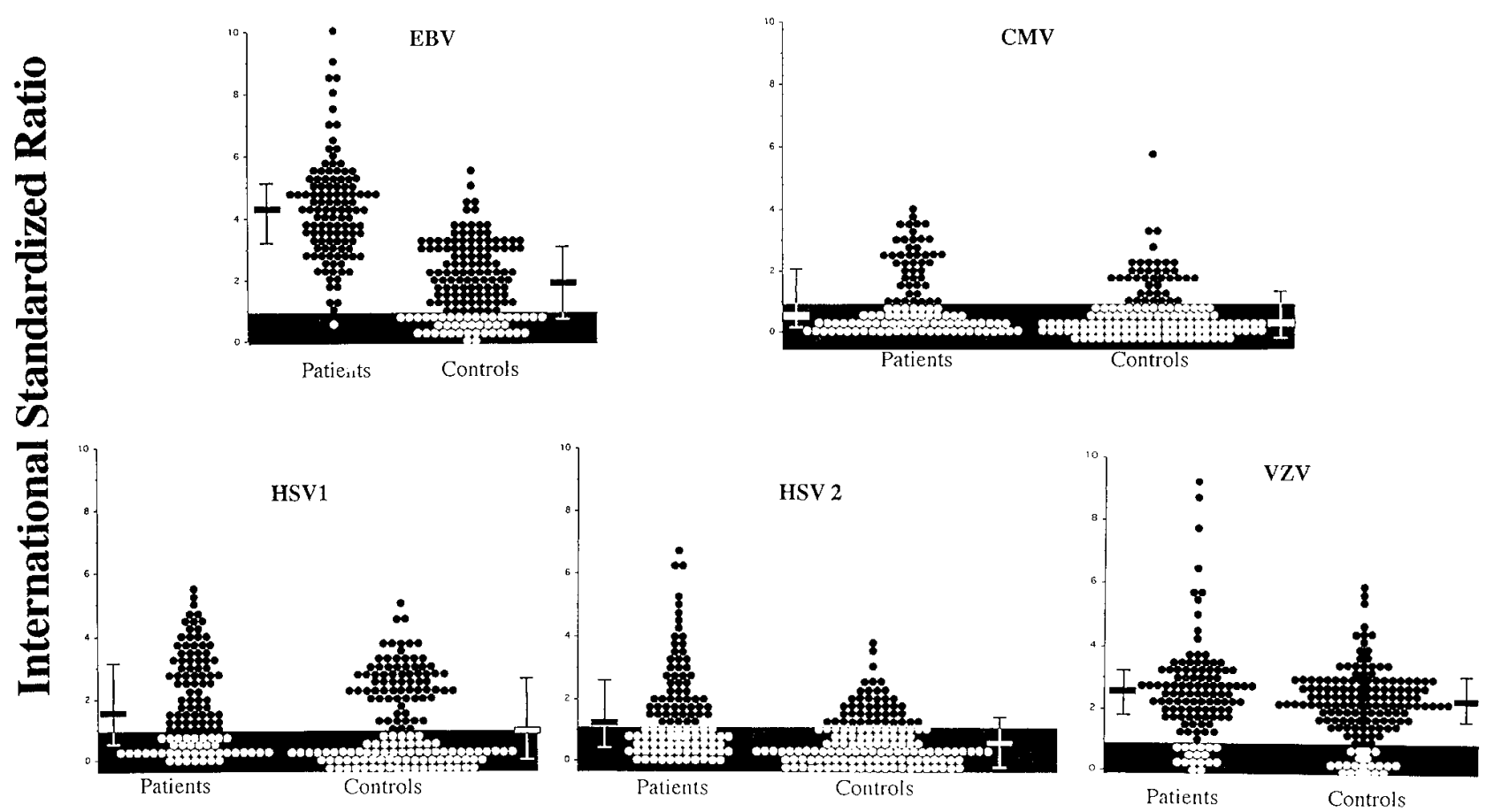

Figure 1. The level of antiviral antibodies. Assays for IgG binding to EBV viral capsid antigen, (EBV), cytomegalovirus $(C M V)$, herpes simplex types 1 and $2(H S V-1$ and $H S V-2)$, and varicella zoster virus $(V Z V)$ are presented for the young lupus patients and their controls, as indicated. The level of antibody is given as ISR. The median and 25-75\% IQRs for the lupus patients and controls are for anti-EBV-VCA 4.30 (1.85) and 1.92 (2.20); for anti-CMV 0.617 (1.74) and 0.508 (1.29); for anti-HSV-1 1.56 (2.58) and 0.924 (2.30); for anti-HSV-2 1.16 (1.64) and 0.557 (1.17); and for anti-VZV $2.53(1.40)$ and $2.39(1.28)$. 
rus infection. A very sensitive assay for Epstein-Barr virus DNA was developed based on previous work $(11,12)$ and by exploiting a nucleotide sequence that is repeated eleven times in the Epstein-Barr virus genome (11).

A total of 32 lupus cases and their matched controls were evaluated for Epstein-Barr virus infection. We asked each case to provide a control matched for age $( \pm 2 \mathrm{yr})$, sex, race, and social circumstances. Seven siblings, 4 cousins, and 12 friends were provided. For those cases that did not provide matched controls, the investigators recruited a matched control (at enrollment, the Epstein-Barr virus seroconversion status of controls was unknown to the investigators). Epstein-Barr virus DNA was assayed in a total of $12 \mu \mathrm{g}$ of mononuclear cell DNA divided into six reactions from each case and control (Fig. 2). Cases and their matched controls were either concordant (Fig. $2 A$ ) for the presence of Epstein-Barr virus DNA, or were dis- cordant (Fig. 2 B) where Epstein-Barr virus DNA was found in one or the other, but not in both. Control experiments demonstrate that DNA is present and unique from each individual in whom Epstein-Barr virus DNA was not detected. Examples of these data are presented in Fig. $2, C-E$.

All 32 lupus cases tested had Epstein-Barr virus DNA. Of the 32 matched controls, 23 had Epstein-Barr virus DNA. In each of the nine discordant pairs, the lupus case had EpsteinBarr virus DNA while the matched control did not (odds ratio $>10$, CI-95\% 2.53- $\infty, P<0.002$; Table III).

All 32 of the lupus cases were seropositive for Epstein-Barr virus, as were 23 of the matched controls. Epstein-Barr virus DNA was demonstrated in the peripheral blood mononuclear cells in every Epstein-Barr virus-seropositive lupus case and control $(n=55)$. Two controls were Epstein-Barr virus-seronegative, and yet had Epstein-Barr virus DNA. One of these
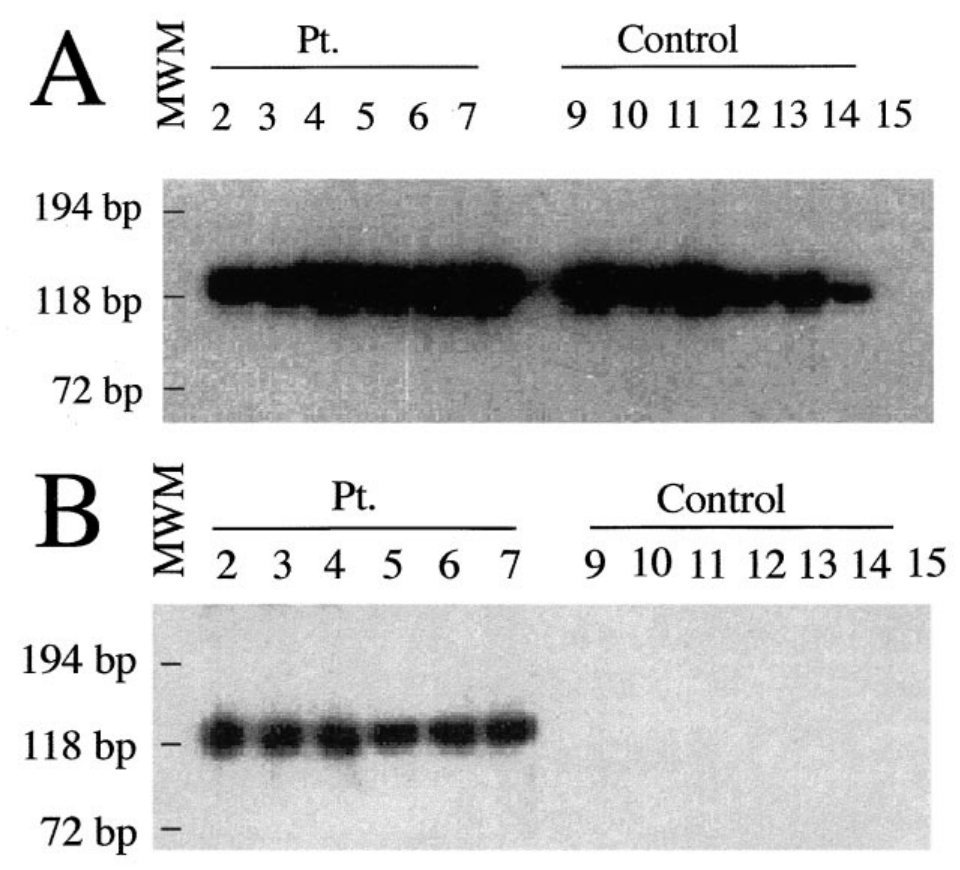

$204 \mathrm{bp}$
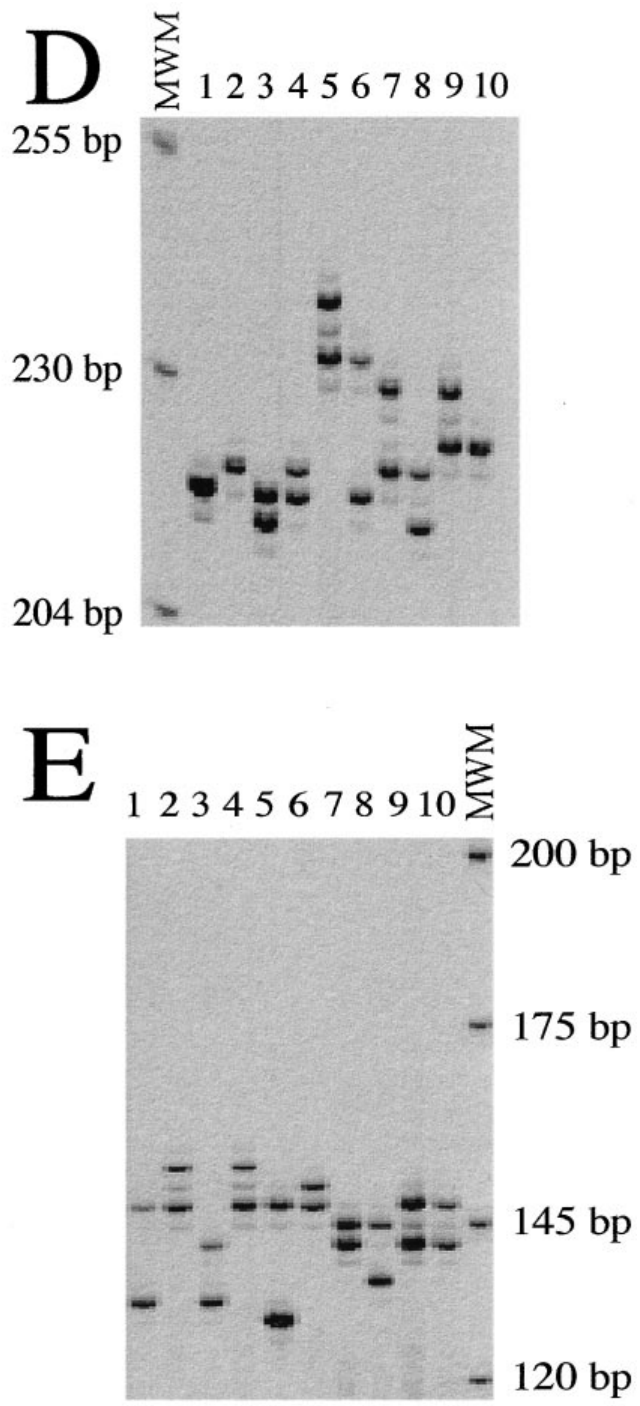

Figure 2. DNA from Epstein-Barr virus in lupus cases and matched controls. A concordant pair where both the case $(A$, lanes $2-7)$ and its matched control (lanes 9-14) have Epstein-Barr virus DNA in every PCR reaction tested. $B$ presents a discordant pair where the lupus case has Epstein-Barr virus DNA (lanes 2-7), while its matched control does not (lanes 9-14). Lane 15 is a control with no added DNA. The products of the PCR using primers from the 60-kD Ro gene (nucleotide nos. 453-472 and 584-565) demonstrate that the PCR conditions will expand DNA in the control subjects who have apparently not been infected by Epstein-Barr virus. $D$ and $E$ present the polymorphisms at D1S1589 and D6S1027 found in the unique DNA from all controls with no Epstein-Barr virus DNA. 
Table III. Detection of DNA from Epstein-Barr Virus in Cases of Pediatric Lupus and their Matched Controls

\begin{tabular}{ccc}
\hline Cases & Controls & Number \\
\hline Present & Present & 23 \\
Present & Absent & 9 \\
Absent & Present & $0^{*}$ \\
Absent & Absent & 0
\end{tabular}

The presence and absence of Epstein-Barr virus DNA in 32 matched sets of lupus patients and controls support an increased frequency of Epstein-Barr virus infection in pediatric lupus. ${ }^{*} P<0.002$, binomial test.

was retested, and had become Epstein-Barr virus-seropositive during the interval between specimens. The second subject was not available for retesting. Consequently, the EpsteinBarr virus DNA assay and Epstein-Barr virus seroconversion assay support the same conclusion: that there is a very close association with Epstein-Barr virus infection and lupus. Indeed, if the difference in the frequency of Epstein-Barr virus infection between controls and lupus patients is because EpsteinBarr virus causes lupus, then from the data in Table I the fraction of lupus cases attributable to Epstein-Barr virus infection is $98 \%(\mathrm{CI}-95 \%, 85-99.7 \%)$.

\section{Discussion}

An association of lupus with Epstein-Barr virus infection has been found. Considered alone, the observed association of lupus with Epstein-Barr virus infection is consistent with three origins: a susceptibility for lupus in Epstein-Barr virus-infected persons, a susceptibility for Epstein-Barr virus infection in patients who previously developed lupus, or a third factor that causes independent susceptibilities to both Epstein-Barr virus infection and to lupus. At this time there is no evidence for such a third factor in this situation, but its existence must remain a formal possibility.

There are no data available to support an unusual and extreme susceptibility to Epstein-Barr virus in young lupus patients, and no mechanism for such a susceptibility is now known. Nevertheless, lupus is characterized by abnormally activated B cells, and a subset of B cells are the target for and site of Epstein-Barr virus infection. Perhaps the intrinsic resistance to Epstein-Barr virus infection is much lower in lupus patients because of the immunoregulatory changes that occur as a consequence of the disease. This possibility could only be eliminated from consideration by the demonstration that EpsteinBarr virus infection almost always precedes the onset of lupus. Unfortunately, no data exist with which to decide this issue. Consequently, a susceptibility to Epstein-Barr virus infection in lupus patients remains a plausible explanation for the observed association.

Fortunately, we are not restricted to considering the association of Epstein-Barr virus infection with lupus in the absence of insights from other work on Epstein-Barr virus or on lupus. Once the influence of confounding technical issues is removed, there is much consistent with the possibility that lupus arises in individuals who have been previously infected with Epstein-
Barr virus, and is no observation that eliminates this possibility from consideration. Indeed, the experiments herein establishing association between Epstein-Barr virus and lupus were attempted as a test of the hypothesis that Epstein-Barr virus is an etiologic factor in the development of lupus. This hypothesis arose from immunochemical studies that suggested some of the critical features for a molecular mechanism, beginning with a structure from Epstein-Barr virus and culminating in one of the forms of lupus autoimmunity $(2,3)$.

The antigenic relationships between peptides from EBNA-1 and $\mathrm{Sm} B / \mathrm{B}^{\prime}(2,3)$ have suggested a possible mechanism for generating antispliceosomal autoimmunity, and may partially describe one of the ways in which Epstein-Barr virus-infected individuals can be predisposed to lupus (Fig. 3). First, EpsteinBarr virus is postulated to infect a susceptible person who is otherwise predisposed by genetics and environment to develop lupus. While virtually all people infected with EpsteinBarr virus develop anti-EBV-VCA antibodies, many also generate antibodies to other viral constituents, including EBNA-1. Among these, it is postulated that a few people may eventually develop antibodies to the PPPGRRP epitope on EBNA-1 which cross-reacts with the PPPGMRPP epitope on the spliceosome. The spliceosome is then processed as an antigen, and is presented to the immune system in a way that has not oc-

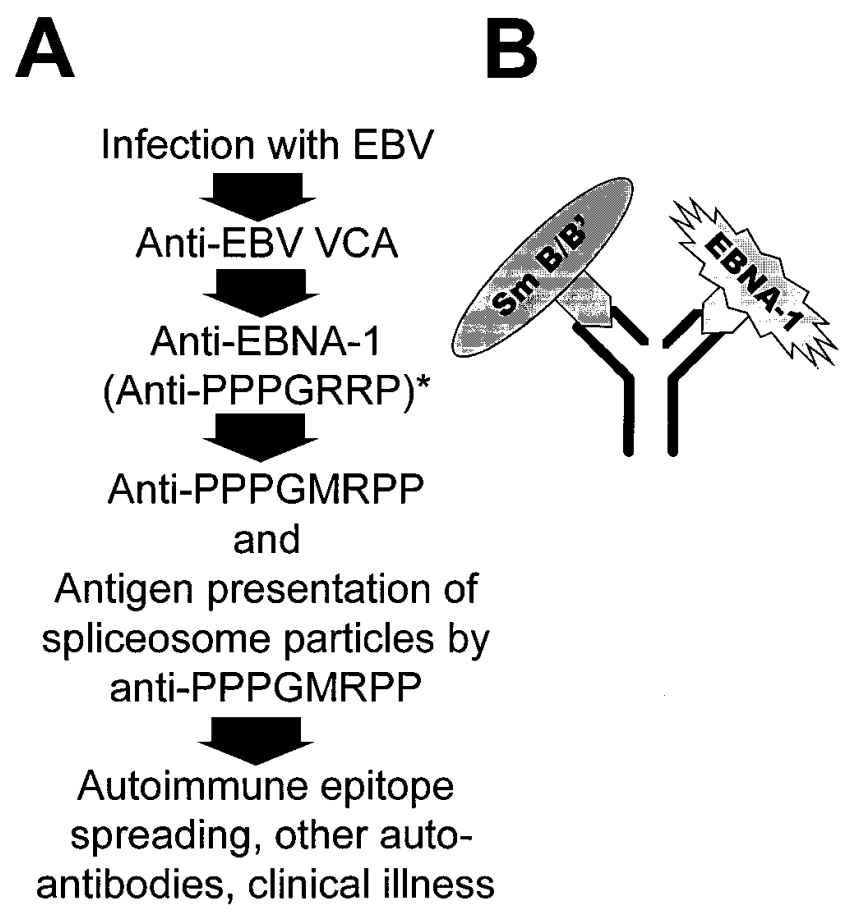

Figure 3. Hypothetical mechanism for association of Epstein-Barr viral infection and development of systemic lupus erythematosus. $(A)$ People genetically susceptible to SLE may mount an unusual immune response $(*)$ to EBNA-1. In one scenario humoral immunity against the PPPGRRP sequence may be a required step $(2,3)$. (B) These antibodies that react with PPPGRRP and cross-react with the PPP-

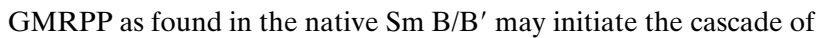
autoimmune responses that spread to different regions of the spliceosomal autoantigens, and result in other autoimmune manifestations, including clinical disease. ( $B$ shows $\operatorname{IgG}$ binding to both $\mathrm{Sm} \mathrm{B} / \mathrm{B}^{\prime}$ and EBNA-1.) 
curred previously, and against which tolerance has either not developed (immune ignorance) or is relatively weak. Lupus autoimmunity and clinical illness then result. There is no requirement in this model for either Epstein-Barr virus or any of the antibodies directed against it to be found in immune complexes, or to be deposited at sites of injury.

The cross-reaction of antibodies capable of binding both PPPGRRP as found in native EBNA-1 and PPPGMRPP as found in the native spliceosome (Fig. $3 B$ ) may be a critical step allowing lupus autoimmunity to develop for some individuals (Fig. $3 A$ ). Under this scenario we immunized animals with the selected peptides as previously reported $(2,3)$. This immunization with peptide bypasses the very complicated immune response against the chronic viral infection out of which lupus autoimmunity arises in the natural state. The peptide immunization directly induces a vigorous immune response against a structure that is capable of setting the immune system on a course toward lupus autoimmunity $(2,3)$. Not only are the anticipated cross-reacting antibodies observed, but also other characteristic features of lupus-like autoimmunity occur in the susceptible animals.

Of course, many steps in this hypothetical scenario for initiating lupus remain to be established. As emphasized above and at the most basic level, if this sequence of events is true, then Epstein-Barr virus infection must precede the onset of lupus. This prediction has not been tested. In addition, whether or not the many humoral autoimmune manifestations of lupus, such as antiribosomal P, anti-Ro (or SS-A), anti-La (or SS-B), or even anti-nRNP, develop by analogous molecular mimicry mechanisms, must necessarily be the subject of other work. Perhaps the binding of La to the EBER RNAs encoded by Epstein-Barr virus and expressed in some infected cells (14) provides an alternative mechanism.

If one accepts that lupus is essentially a humoral autoimmune disease, then another prediction of the hypothesis that Epstein-Barr virus causes lupus is that the immune response against the virus must have critical distinguishing characteristics that would allow lupus autoimmunity to be initiated. At most, we could consider present knowledge to provide only suggestive clues for what these critical distinguishing characteristics might be. On the other hand, there are many differences between lupus patients and normal controls in their immune responses to Epstein-Barr virus, consistent with the existence of lupus autoimmunity-inducing differences in the immune response.

For example, when comparing lupus sera to control sera, several investigators have detected increases in the level or differences in the fine specificity of anti-early antigen, antimembrane antigen, anti-EBNA-1, EBNA-2, or EBNA-3 (15-20). In two studies these findings do not appear to be explained by polyclonal B cell activation, since titers to other antigens, measured concurrently, were not elevated $(18,20)$. In addition, the only published study systematically examining the immune response to EBNA-1 peptides outside of the glycine-alanine repeat showed several significant differences between adult lupus patients and normal controls (18). Of the 11 different peptides studied, 3 of these peptides were commonly bound by lupus patient sera at a higher level than that found in normal control sera. In addition, the increased binding to PPPGRRP (from EBNA-1) by lupus sera containing anti-Sm and antinRNP has also been appreciated (21). Recent preliminary studies from our laboratory with over 400 overlapping oc- tapeptides spanning the EBNA-1 protein show that pediatric lupus patient sera consistently bind different regions of EBNA-1 than do their matched, anti-EBV-VCA-positive controls (J.A. James and J.B. Harley, unpublished data). Among these differences is the tendency for normal sera to bind the glycine-alanine repeat of EBNA-1 while lupus sera do not generally bind this amino acid repeat. In contrast, a glycinearginine repeat that is found in both EBNA-1 and Sm D is more antigenic for lupus sera than it is in control sera (22-26). These findings are consistent with the possibility that there may be multiple antigenic relationships between lupus and Epstein-Barr virus, and that critical ones vary among lupus patients.

Other features that may allow or encourage a role for Epstein-Barr virus in lupus include virus latency (4) and deficiency in the $\mathrm{T}$ cell immune suppression required to contain this infection. In a study by Tsokos et al. (27), T cells of SLE patients have been shown to be deficient in their ability to suppress the outgrowth of Epstein-Barr virus-infected B cells from in vitro-infected peripheral blood cells. Latency and the immune response against the virus are different aspects of the same process; the virus has many molecular features that appear to encourage latency and discourage an infection-terminating immune response. The glycine-alanine repeat appears to be responsible for the described defects in antigen processing of EBNA-1 (28). Indeed, normal individuals do not mount cytotoxic T cell responses against EBNA-1 (28). Apparently, the glycine-alanine repeat of EBNA-1 appears to inhibit HLA class I peptide presentation from EBNA-1, thereby inhibiting $\mathrm{T}$ cell immunity against this antigen (28). This incompletely understood effect may profoundly influence the immune response, though its importance to the pathogenesis of lupus is not known.

Epstein-Barr virus has an IL-10-like gene that has many similar and some different activities relative to human IL-10 (29). For example, both human and viral IL-10 inhibit apoptosis in $\mathrm{T}$ cells recovered from patients with infectious mononucleosis (30). Clearly, viral IL-10 has the potential to influence the immune response to the virus $(31,32)$.

Epstein-Barr virus also infects B cells, which then become dysregulated and proliferate. Indeed, apoptosis of B cells is abnormal as a consequence of Epstein-Barr virus infection which, thereby, has the potential to favor development of autoimmunity (33). Epstein-Barr virus can increase B cell survival of latently infected cells both by upregulating cellular bcl-2 and through an Epstein-Barr virus-encoded protein, BHRF1. BHRF1 has amino acid sequence similarity and a molecular action similar to $b c l-2$ in that this gene inhibits apoptosis in B cells (34). Interestingly, when transgenic mice are stimulated to overproduce $b c l-2$ they develop a syndrome of lupus-like autoimmunity and immune complex-mediated, cresentic glomerulonephritis (35). Epstein-Barr virus infection is also well known to induce the production of autoantibodies during acute infection $(25,36)$.

When the association between Epstein-Barr virus and lupus described herein is considered in the context of other studies, the aggregate of what is known is consistent with the intriguing possibility that Epstein-Barr virus infection is required, but not alone sufficient, for development of systemic lupus erythematosus in most patients. We look forward to the results of those subsequent experiments that will support and establish or disprove this hypothesis. 


\section{Acknowledgments}

We are grateful to the many patients, controls, and the physicians who cooperated with this study, especially Drs. Craig Carson, Katherine Madson, Rita Jareth, Timothy Shaver, Robert McArthur, Alan Martin, Fred Delafield, Ira Targoff, Fred Miller, Lisa Rider, Morris Reichlin, the Oklahoma Lupus Foundation, and the Childhood Myositis Heterogeneity Study. We appreciate the statistical advice of Dr. Barbara Neas and the assistance of Tim Gross, Jody Gross, Micah McClain, Amber Nelson, Monica Kirby, Diana Bozalis, and Gail Brunner, R.N. We are grateful to Morris Reichlin, Robert Rich, John Vaughan, and two anonymous reviewers for their criticisms of an earlier version of the manuscript.

This study was supported by the National Institutes of Health (AR42474, AR42460, AI424717, AR01981, GM08237, AI31584) and the U.S. Department of Veterans Affairs.

\section{References}

1. Tan, E.M., A.S. Cohen, J.F.Fries, A.T. Masi, D.J. McShane, N.F. Rothfield, J.G. Schaller, N. Talal, and R.J. Winchester. 1982. The 1982 revised criteria for the classification of systemic lupus erythematosus. Arthritis Rheum. 25: 1271-1277.

2. James, J.A., T. Gross, R.H. Scofield, and J.B. Harley. 1995. PPPGMRPP immunization generates anti-Sm humoral autoimmunity and induces systemic lupus erythematosus in rabbits. J. Exp. Med. 181:453-461.

3. James, J.A., R.H. Scofield, and J.B. Harley. 1997. Lupus humoral autoimmunity after short peptide immunization. Ann. NY Acad. Sci. 815:124-127.

4. Evans, A.S., and J.C. Niederman. 1989. Epstein-Barr virus. In Viral Infections of Humans, Epidemiology and Control. A.S. Evans, editor. Plenum Publishing Corporation, New York. 265-292.

5. Evans, A.S., N.F. Rothfield, and N.F. Niederman. 1971. Raised antibody titers to E.B. virus in systemic lupus erythematosus. Lancet. i:167-168.

6. Klipple, J.H., J.L. Decker, P.M. Grimley, A.S. Evans, and N.F. Rothfield. 1973. Epstein-Barr virus antibody and lymphocyte tubuloreticular structures in systemic lupus erythematosus. Lancet. i:1057-1058.

7. Rothfield, N.F., A.S. Evans, and J.C. Niederman. 1973. Clinical and laboratory aspects of raised virus antibody titers in systemic lupus erythematosus. Ann. Rheum. Dis. 32:238-245.

8. Harley, J.B., A.S. Sestak, L.G. Willis, S.M. Fu, J.A. Hansen, and M. Reichlin. 1989. A model for disease heterogeneity in systemic lupus erythematosus. Relationships between histocompatibility antigens, autoantibodies and lymphopenia or renal disease. Arthritis Rheum. 32:413-419.

9. James, J.A., and J.B. Harley. 1996. Human lupus anti-spliceosome A protein autoantibodies bind contiguous surface structures and segregate into two sequential epitope binding patterns. J. Immunol. 156:4018-4026.

10. Stafford, H.A., C.J. Anderson, and M. Reichlin. 1995. Unmasking of anti-ribosomal $P$ autoantibodies in healthy individuals. J. Immunol. 155:27542761.

11. Saito, I., B. Dervenius, T. Compton, and R.I. Fox. 1989. Detection of Epstein-Barr virus DNA by polymerase chain reaction in blood and tissue biopsies from patients with Sjogren's syndrome. J. Exp. Med. 169:2191-2198.

12. Miyashita, E.M., B. Yang, K.M.C. Lam, D.H. Crawford, and D.A. Thorley-Lawson. 1995. A novel form of Epstein-Barr virus latency in normal B cells in vivo. Cell. 80:593-601.

13. Sanger, F. , S. Nicklen, and A.R. Coulson. 1977. DNA sequencing with chain-terminating inhibitors. Proc. Natl. Acad. Sci. USA. 74:5463-5467.

14. Lerner, M.R., N.C. Andrews, G. Miller, and J.A. Steitz. 1981. Two small RNAs encoded by Epstein-Barr virus and complexed with protein are precipitated by antibodies from patients with systemic lupus erythematosus. Proc. Natl. Acad. Sci. USA. 78:805-809.

15. Sculley, D.G., T.B. Sculley, and J.H. Pope. 1986. Reactions of sera from patients with rheumatoid arthritis, systemic lupus erythematosus and infectious mononucleosis to Epstein-Barr virus-induced polypeptides. J. Gen. Virol. 67: 2253-2258.

16. Kitagawa, H., S. Iho, Y. Takashi, and T. Hoshino. 1988. Detection of antibodies to the Epstein-Barr virus nuclear antigens in the sera from patients with systemic lupus erythematosus. Immunol. Lett. 17:249-252.

17. Yokochi, T., A. Yanagawa, Y. Kimura, and Y. Mizushima. 1989. High titer of antibody to the Epstein-Barr virus membrane antigen in sera from patients with rheumatoid arthritis and systemic lupus erythematosus. J. Rheumatol. 16:1029-1032.

18. Petersen, J., G. Rhodes, J. Roudier, and J.H. Vaughan. 1990. Altered immune response to glycine-rich sequences of Epstein-Barr nuclear antigen-1 in patients with rheumatoid arthritis and systemic lupus erythematosus. Arthritis Rheum. 33:993-1000.

19. Ngou, J., M. Segondy, J.-M. Seigneurin, and H. Graafland. 1990. Antibody responses against polypeptide components of Epstein-Barr virus-induced early diffuse antigen in patients with connective tissue disease. J. Med. Virol. 32: $39-46$.

20. Ngou, J., H. Graafland, and M. Segondy. 1992. Antibodies against polypeptides of purified Epstein-Barr virus in sera from patients with connective tissue diseases. J. Autoimmun. 5:243-249.

21. James, J.A., and J.B. Harley. 1992. Linear epitopes mapping of an Sm B/B' polypeptide. J. Immunol. 148:2074-2079.

22. James, J.A., M.J. Mamula, and J.B. Harley. 1994. Sequential autoantigenic determinants of the small nuclear ribonucleoprotein Sm D are shared by human lupus autoantibodies and MRL lpr/lpr antibodies. Clin. Exp. Immunol. 98:419-426.

23. Sabbatini, A., S. Bombardieri, and P. Migliorini. 1993. Autoantibodies from patients with systemic lupus erythematosus bind a shared sequence of $\mathrm{Sm}$ D and Epstein-Barr virus-encoded nuclear antigen EBNA-1. Eur. J. Immunol. 23:1146-1152.

24. Marchini, B., M.P. Dolcher, A. Sabbatini, G. Klein, and P. Migliorini. 1994. Immune response to different sequences of the EBNA-1 molecule in Epstein-Barr virus-related disorders and in autoimmune diseases. J. Autoimmun. 7:179-191.

25. Rivkin, E., M. Vella, and R.G. Lahita. 1994. A heterogeneous immune response to an SmD-like epitope by SLE patients. J. Autoimmun. 7:119-132.

26. Vaughan, J.H., M.-D. Nguyen, J.R. Valbracht, K. Patrick, and G.H. Rhodes. 1995. Epstein-Barr virus-induced autoimmune responses. II. Immunoglobulin $\mathrm{G}$ autoantibodies to mimicking and nonmimicking epitopes. Presence in autoimmune disease. J. Clin. Invest. 95:1316-1327.

27. Tsokos, G.C., I.T. Magrath, and J.E. Balow. 1983. Epstein-Barr virus induces normal B cell responses but defective suppresser $\mathrm{T}$ cell responses in patients with systemic lupus erythematosus. J. Immunol. 131:1797-1801.

28. Levitskaya, J., M. Coram, V. Levitsky, S. Imreh, P.M. SteigerwaldMullen, and M.G. Masucci. 1995. Inhibition of antigen processing by the internal repeat region of the Epstein-Barr virus nuclear antigen-1. Nature. 375:685688.

29. Ying, L., R. de Waal Malefyt, F. Briere, C. Parhem, J.M. Bridon, J. Banchereau, K.W. Moore, and J. Xu. 1997. The EBV IL-10 homologue is a selective agonist with impaired binding to the IL-10 receptor. J. Immunol. 158: 604-613.

30. Taga, K., J. Chretien, B. Cherney, L. Diaz. M. Brown, and G. Tosada. 1994. Interleukin-10 inhibits apoptotic cell death in infectious mononucleosis $t$ cells. J. Clin. Invest. 94:251-260.

31. de Waal Malefyt, R., J. Haanen, H. Spits, M.-G. Roncarlo, A. te Velde, C. Figdor, K. Johnson, R. Kastelein, H. Yssl, and J.E. de Vreis. 1991. Interleukin 10 (IL-10) and viral IL-10 strongly reduce antigen-specific human T cell proliferation by diminishing the antigen-presenting capacity of monocytes via down regulation of class II major histocompatibility complex expression. $J$. Exp. Med. 178:439-447.

32. Miyazaki, I., R.K. Cheung, and H.M. Dosch. 1993. Viral interleukin 10 is critical for the induction of B cell growth transformation by Epstein-Barr virus. J. Exp. Med. 178:439-447.

33. Gregory, C.D., C. Dive, S. Henderson, C.A. Smith, G.T. Williams, J. Gordon, and A.B. Rickinson. 1991. Activation of Epstein-Barr virus latent genes protects human B cells from death by apoptosis. Nature.349:612-614.

34. Henderson, S., D. Huen, M. Rowe, C. Dawson, G. Johnson, and A. Rickinson. 1993. Epstein-Barr virus-coded BHRF1 protein, a viral homologue of Bcl-2, protects human B cells from programmed cell death. Proc. Natl. Acad. Sci. USA. 90:8479-8483.

35. Strasser, A., S. Whittingham, D.L. Vaux, M.L. Bath, J.M. Adams, S. Cory, and A.W. Harris. 1991. Enforced BCL2 expression in B-lymphoid cells prolongs antibody responses and elicits autoimmune disease. Proc. Natl. Acad. Sci. USA. 88:8661-8665.

36. Vaughan, J.H. 1995. The Epstein-Barr virus in autoimmunity. Springer Semin. Immunopathol. 17:203-230. 